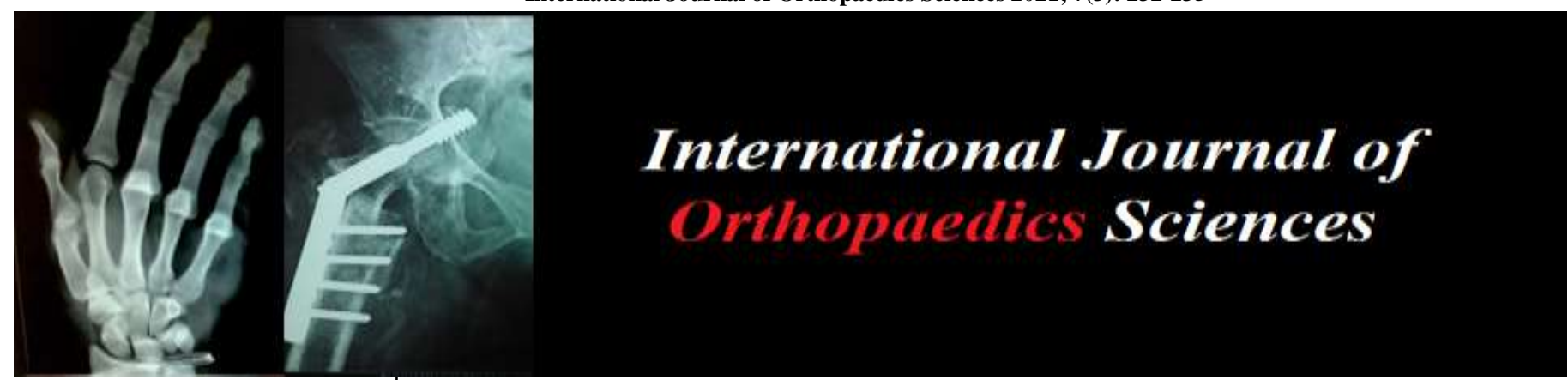

E-ISSN: 2395-1958

P-ISSN: 2706-6630

IJOS 2021; 7(3): 232-235

(C) 2021 IJOS

www.orthopaper.com

Received: 07-05-2021

Accepted: 09-06-2021

Balakrishnan Sushant Assistant Professor,

Department of Orthopaedics,

SUT Academy of Medical

Sciences, Vencode, Vattapara,

Thiruvananthapuram, Kerala

India

Dr. E Kaizar Ennis

Assistant Professor,

Department of Orthopaedics SUT Academy of Medical

Sciences, Vencode, Vattapara

Thiruvanthapuram, Kerala, India
Corresponding Author: Dr. E Kaizar Ennis Assistant Professor, Department of Orthopaedics SUT Academy of Medical Sciences, Vencode, Vattapara Thiruvanthapuram, Kerala, India

\section{Clinico-radiological study of healing of diaphyseal fractures of tibia treated by interlocking intramedullary nail: A hospital based prospective study}

\author{
Balakrishnan Sushant and Dr. E Kaizar Ennis
}

DOI: https://doi.org/10.22271/ortho.2021.v7.i3d.2751

Abstract

Background: Tibial diaphyseal fractures are one of the most commonest fractures in young adults around the world. It is usually managed surgically by using interlocking intramedullary nails. The present study is aimed to evaluate the Clinico-Radiological Healing of Diaphyseal Fractures of Tibia Treated by Interlocking Intramedullary Nail.

Materials and Methods: The study was done in the Department of Orthopaedic Surgery, SUT Academy of Medical Sciences, Vattapara, Kerala over a period 18 months from October 2019 to March 2021. Twenty-eight patients were included in the study based on the inclusion and exclusion criteria. All the patients were explained regarding the procedure, study and informed consent was obtained. Demographic, clinical data and 12th month results was recorded. The collected data was analysed by SPSS (20.0) version software.

Results: Half of the study group were aged between 21-30 years ( $n=14)$ with male female ratio was 14:1. Fourteen patients had closed type of fracture. Oblique type of fracture pattern was the most commonest compared to others. Twenty-three patients had fracture due to road traffic accident and middle third was the most commonest site of fracture. Most patients underwent surgery within 36-48 hours of injury. At 12th month of assessment, 24 patients had fracture union while 2 patients had delayed union and 2 patients had non-union. Functional grading showed excellent results in 19 patients and good results in 5 patients.

Conclusion: Interlocking intramedullary nailing is still a valid technique for the management of tibial diaphyseal fractures since its inception.

Keywords: intramedullary, interlocking, nail, tibia, diaphyseal, Grosse-kempt, Gustilo Anderson

\section{Introduction}

The diaphyseal fractures of tibia are amongst the most common long bone injuries. Because of its subcutaneous location, it is often challenging to manage an open fracture and all the complications associated with it ${ }^{[1]}$. The treatment goal of the tibial diaphyseal fractures is to achieve union with correct lenght, alignment and restoration of normal knee and ankle mechanics as well as regaining early autonomous ambulation. This can be achieved by either conservative treatment or by surgery. One of the surgical methods is by using closed interlocking intramedullary nailing. Grosse-Kempf locking intramedullary nail was introduced in 1974. It permits wider indications for tibia nailing to proximal and distal fractures and enables simultaneous treatment of unstable fractures in length and rotation to stabilize diaphyseal fractures. Intramedullary nailing has gained wide acceptance in the management of both closed and open fractures of Gustilo Anderson Type I and II. Following closed reduction, reaming of tibia allows the insertion of a large diameter nail, which confers more stability, allows much earlier weight bearing, and limits the risk of a second operation. Excellent union rates have been reported with minimal complications. The assessment of the healing of tibial fractures relies on serial radiographical examinations with clinical correlations [2]. Augusto Sarmiento specified that for successful union in the tibia following criteria must be observed: a) the ability of the patient to bear weight painlessly b) the absence of clinically detectable movement at the site of fracture c) visible bridging callus across the fracture on plain radiography ${ }^{[3-5]}$. 
Despite the large number of studies of tibial fractures which have used healing as an outcome measure, there is disagreement on the precise definition of union. Intramedullary fixation can make the decision as to when tibial fractures have healed even more difficult ${ }^{6,7}$. Clinical examination becomes less useful since stiffness, as assessed by movement at the site of fracture, is often not detectable in the presence of an intramedullary nail which can obscure bony details on the radiograph and interfere with the assessment of callus and the fracture line8. Several variables are consistently noted when considering radiological union, including the amount and quality of callus, the presence of bridging callus over fracture line, and the trabecule which cross it. Numerous investigations have considered bridging callus on two views as a definition of union. The purpose of the present study is to evaluate the fracture healing of tibial fractures treated by intramedullary interlocking nail using clinical and radiological methods.

\section{Materials and Methods \\ Study settings and Period}

The present prospective study was conducted in the Department of Orthopaedic Surgery, SUT Academy of Medical Sciences, Vattapara, Kerala over a period 18 months from October 2019 to March 2021 in patients having diaphyseal fracture of tibia (with or without fracture of fibula), operated in this institute, after the approval of the ethical board of the institute in accordance with the standard of the Helsinki declaration.

\section{Inclusion criteria}

- Diaphyseal fracture of tibia with or without fracture of fibula in healthy adults

- Patients treated with interlocking intramedullary nails within a period of three days.

\section{Exclusion criteria}

- Patients with comminuted fractures of tibia

- Gustilo and Anderson Type III open fractures

- Ipsilateral femur fractures

- Compromised vascularity

- Local or systemic infection

- Any previous bony surgery to the same tibia

- Unsolvable deformities, disabilities and lesions of the affected limb affecting locomotion

- Metabolic or any other diseases affecting the healing process

\section{Procedure}

The study included 28 patients based on the inclusion and exclusion criteria. All the patients were explained the procedure, study method and informed consent was obtained at the onset of study. All the demographic data (age, sex and mode of injury), clinical data such as Gustilo Anderson classification of injury, site and pattern of fracture were recorded. The patients were subjected to interlocking intramedullary nailing procedure as per standard methods. The injury -surgery time was recorded. The patient was examined clinically and radiological data collected over 12 months and analysed.

\section{Statistical analysis}

The data was expressed in number, percentage, mean and standard deviation. Statistical Package for Social (SPSS 20.0) version for statistical analysis. Chi square test applied to find the statistical significant. $\mathrm{p}$ value less than 0.05 considered statistically significant at $95 \%$ confidence interval.

\section{Results}

The study included a total of 28 patients. Half the patients $(\mathrm{n}=14)$ were aged between 21-30 years and 5 patients were aged was between 31-40years. Males $(n=26)$ were more compared to females $(n=2)$ (Table 1). Fifty percent patients had closed type of fracture $(n=14), 9$ had open G\&A type-I and 5 had open G\&A type-II. Most patients had oblique type fracture pattern compared to other patterns of fractures. Twenty-three patients had road traffic accident (10 had closed type, 9 G\&A type-I and 4 G\&A type-II). Two patients fell from the height had closed and type-II grading each. Slip on floor was the cause for closed injury in 3 patients (Table-2). Maximum patients had fracture at middle third compared to proximal and distal (Graph-2). Eight patients underwent surgery within 36-48 hrs of injury, 2 patients within 12 hours and 4 patients had a injury-surgery interval of 60-72 hrs (Table-3). A total of 12 patients underwent dynamization of nail of which 6 were closed and 6 were of G\&A type-I. At six months 3 of them in closed type showed delayed union and 3 others had union. In G\&A type-I, 5 had union and only one had delayed union (Table-4). In the functional grading analysis 9 patients in closed type had excellent results 2 had good result, 1 had fair result and 2 had poor result. Five patients with GA type-I had excellent result, 3 good and 1 fair result. All 5 patients with GA type II injury had excellent results. Overall analysis revealed 19 excellent, 5 good, 2 fair and 2 poor results (Table-5).

Table 1: Distribution of patients based on the demographic data

\begin{tabular}{|c|c|c|}
\hline Demographic data & Number & Percentage (\%) \\
\hline Age (Years) & & \\
\hline $21-30$ & 14 & 50.00 \\
\hline $31-40$ & 5 & 17.80 \\
\hline $41-50$ & 1 & 3.50 \\
\hline $51-60$ & 4 & 14.20 \\
\hline $61-70$ & 3 & 10.70 \\
\hline $71-80$ & 1 & 3.50 \\
\hline Gender & & \\
\hline Male & 26 & 92.80 \\
\hline Female & 2 & 7.10 \\
\hline Type of fracture & & \\
\hline Closed & 14 & 50.00 \\
\hline Open G\&A type-I & 9 & 32.10 \\
\hline Open G\&A type II & 5 & 17.80 \\
\hline
\end{tabular}

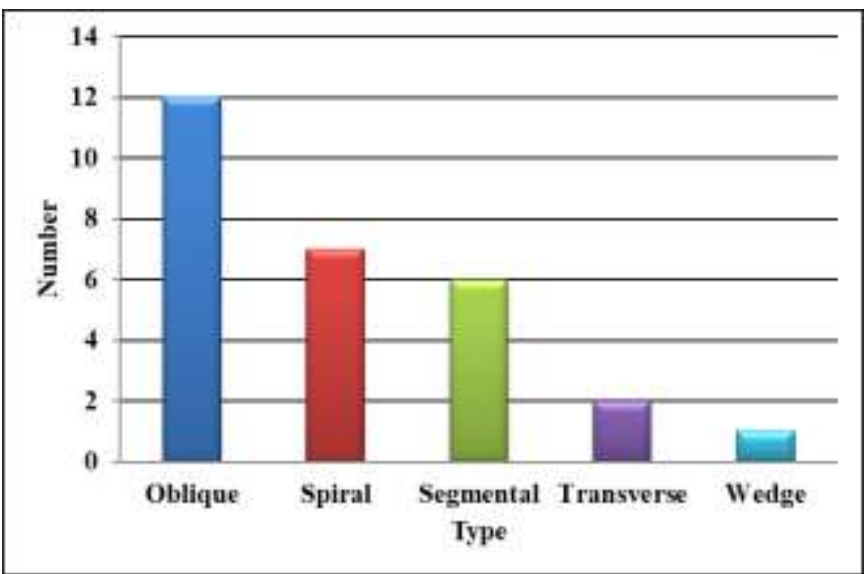

Graph 1: Distribution of patients based on fracture 
Table 2: Mode of injury and gustilo Anderson grading

\begin{tabular}{|c|c|c|c|c|}
\hline Mode of injury & Number & Closed & Type-I & Type-II \\
\hline Road traffic accident & 23 & 10 & 9 & 4 \\
\hline Fall from height & 2 & 1 & 0 & 1 \\
\hline Slip on floor & 3 & 3 & 0 & 0 \\
\hline Total type of wounds & 28 & 14 & 9 & 5 \\
\hline
\end{tabular}

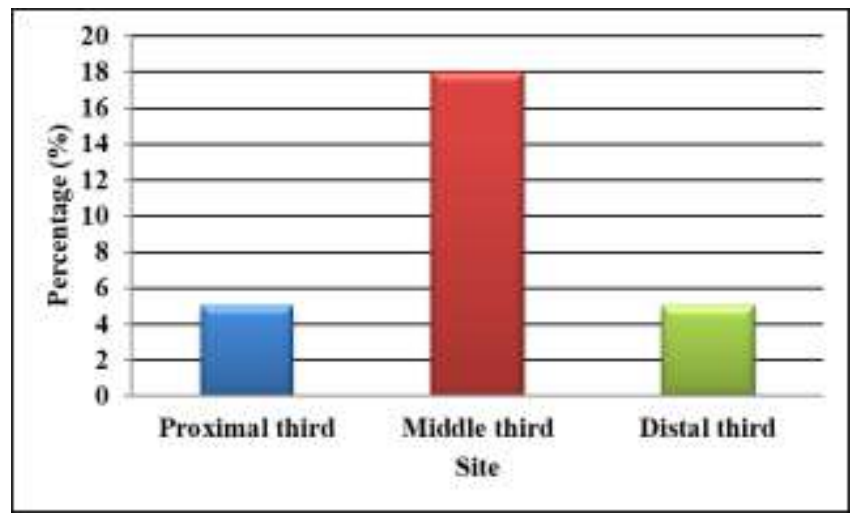

Graph 2: Site of fracture

Table 3: Type of surgery and surgery interval

\begin{tabular}{|c|c|c|}
\hline Injury-surgery interval (Hours) & Number & Percentage (\%) \\
\hline$>12 \mathrm{hrs}$ & 2 & 7.10 \\
\hline $12-24 \mathrm{hrs}$ & 3 & 3.50 \\
\hline $24-36 \mathrm{hrs}$ & 4 & 14.20 \\
\hline $36-48 \mathrm{hrs}$ & 8 & 28.50 \\
\hline $48-60 \mathrm{hrs}$ & 7 & 25.00 \\
\hline $60-72 \mathrm{hrs}$ & 4 & 14.20 \\
\hline \multicolumn{2}{|l}{} \\
\hline
\end{tabular}

Table 4: Results of dynamized cases

\begin{tabular}{|c|c|c|c|c|c|c|}
\hline \multirow{2}{*}{$\begin{array}{c}\text { Type of } \\
\text { injury }\end{array}$} & \multirow{2}{*}{$\begin{array}{c}\text { Number } \\
\text { of cases }\end{array}$} & \multirow{2}{*}{$\begin{array}{c}\text { Percentage } \\
(\boldsymbol{\%})\end{array}$} & & \multicolumn{4}{|c|}{ Results at 6 months } \\
\cline { 4 - 7 } & & & \multicolumn{2}{|c|}{ Delayed } & \multicolumn{2}{|c|}{ Union } \\
\cline { 4 - 7 } & & $\mathbf{n}$ & $\boldsymbol{\%}$ & $\mathbf{n}$ & $\boldsymbol{\%}$ \\
\hline Closed & 6 & 21.10 & 3 & 10.70 & 3 & 10.70 \\
\hline Open type I & 6 & 21.10 & 1 & 3.50 & 5 & 17.80 \\
\hline
\end{tabular}

Table 5: Distribution of patients based functional grade

\begin{tabular}{|c|c|c|c|c|c|}
\hline Criteria & Closed & $\begin{array}{c}\text { Type- } \\
\text { I }\end{array}$ & $\begin{array}{c}\text { Type- } \\
\text { II }\end{array}$ & Number & $\begin{array}{c}\text { Percentage } \\
(\mathbf{\%})\end{array}$ \\
\hline Excellent & 9 & 5 & 5 & 19 & 67.80 \\
\hline Good & 2 & 3 & 0 & 5 & 17.80 \\
\hline Fair & 1 & 1 & 0 & 2 & 7.10 \\
\hline Poor & 2 & 0 & 0 & 2 & 7.10 \\
\hline
\end{tabular}

Table 6: Distribution of patients based on the final outcomes after $12^{\text {th }}$ month

\begin{tabular}{|c|c|c|c|c|c|c|c|c|}
\hline \multirow{2}{*}{ Type of injury } & \multicolumn{2}{|c|}{ Union } & \multicolumn{2}{|c|}{ Delayed union } & \multicolumn{2}{|c|}{ Non union } & \multicolumn{2}{|c|}{ Number } \\
\cline { 2 - 9 } & $\mathbf{n}$ & $\mathbf{\%}$ & $\mathbf{n}$ & $\mathbf{\%}$ & $\mathbf{n}$ & $\boldsymbol{\%}$ & $\mathbf{n}$ & $\boldsymbol{\%}$ \\
\hline Closed & 11 & 39.20 & 1 & 3.5 & 2 & 7.10 & 14 & 50.00 \\
\hline G\&A Type-I & 8 & 28.50 & 1 & 3.5 & 0 & 0.00 & 9 & 32.10 \\
\hline G\&A Type-II & 5 & 17.80 & 0 & 0.00 & 0 & 0.00 & 5 & 17.80 \\
\hline Number & 24 & 85.70 & 2 & 7.10 & 2 & 7.10 & 28 & 100.00 \\
\hline
\end{tabular}

\section{Discussion}

The main aim of treatment of a fracture is to restore the full function of the part as early as possible. There are many factors which influence the treatment of fracture and there by the outcome, such as age of the patient, type of fracture, site of fracture, fracture geometry and degree of commination. If a suitable method is not chosen, then there would be a higher chance of prolonged morbidity and thereby disability. There are various methods available for treatment of fractures of diaphysis of tibia ${ }^{[9]}$. Each method has its merits and demerits. These methods vary from conservative management with Plaster of Paris cast immobilization to surgical methods. The surgical method can be external fixation or internal fixation. External fixation is mainly used for open fractures of Gustilo and Anderson type III injuries while internal fixation is used for closed, type I and II open fractures. Closed method of intramedullary nailing for shaft of tibia provides a favourable method of fracture healing ${ }^{[10]}$. It does not disturb the fracture hematoma and avoids the periosteal stripping which is quite favourable for fracture healing. The technique of closed intramedullary nailing has been more successful and easier with the onset of use of image intensifiers during surgery, as it helps in avoiding any malunion and rotational deformity ${ }^{[11]}$. In the present study, twenty-eight patients with closed, type-1 and type-II tibial fractures were evaluated clinically and radiologically for union following reamed interlocking intramedullary nail. Keating et al. in a similar study found the average age of the patient to be 37 years, ranging from 16 years to 88 years ${ }^{[12]}$. In our study, 26 were male and 2 were females. The male female ratio is $13: 1$. In a similar study by Wiss et al., there were 81 males $(73 \%)$ and 27 females $(25 \%)$ [13]. This may be attributed to the fact that Indian males are more active in outdoor activities than females. In our series, 22 cases were with injury in the right lower limb while the remaining 6 cases had injury in the left lower limb. The ratio of right limb involvement was 3.6:1. This may be due to the fact that right side the dominant side in most of the people and during road traffic accident and slips, the brunt of the injury falls more on the dominant side. This suggests that tibial fractures commonly occur due to high energy trauma commonly seen in road traffic accidents. The commonest site of fracture in the shaft of tibia was in the middle third as seen in 15 patients $(53.5 \%)$. This was followed to 4 patients $(14.2 \%)$ with fractures in the proximal third of the shaft and 3 patients $(10.7 \%)$ with fracture in the lower third of the shaft of tibia. Six patients $(21.4 \%)$ had segmental fractures. Sedlin et $a l$., in their study in 1985 had $61.9 \%$ fractures in the middle third, $4.8 \%$ in the proximal third and $22.3 \%$ fractures in the distal third of shaft of tibia. 2 Segmental fractures were seen in $11 \%$ cases ${ }^{[14]}$. Gustilo \& Anderson type I open fracture was present in $32.1 \%$ and $10.7 \%$ had type II open fractures. Pandey et.al., in 1978 had $73 \%$ closed and $27 \%$ open fractures of tibia in their study. Type III injuries cause disturbances in bony vascularity as well as soft tissue damage and due to the contamination, has higher incidence of infection, hampering the study of normal bony union after treatment with interlocking intramedullary nail hence were excluded from the present study ${ }^{[15]}$. In our study, oblique pattern of fracture was the commonest, seen in 12 cases $(42.8 \%)$, spiral in 7 cases $(25 \%)$, segmental in 6 cases $(21.4 \%)$, transverse in 2 $(7.1 \%)$ and wedge type in 1 case $(3.5 \%)$. Hooper et.al., in a study in which closed intramedullary nail was used to treat fractures, $45 \%$ cases were oblique, $3.5 \%$ were spiral, $3.5 \%$ were Segmental and $48 \%$ were segmental ${ }^{[16]}$. Oblique and spiral fractures accounted for $67.8 \%$ of the total cases in our study, suggesting that these are the commonest fracture geometry seen in tibial fractures. In our study, only 2 patients were operated within the 12 hours of sustaining the fracture. More than $80 \%$ of the surgical management took day after sustaining the injury. The delay in surgery place in the 2 nd or 3rd was probably because, our institute is a tertiary referral centre. The time also varied according to local condition of the limb and any associated injury. Out of 28 patients, 26 had an ipsilateral fracture of fibula. Surgical fixation of fibula was 
done in 4 patients, using closed intramedullary $\mathrm{K}$ wire insertion in 3 patients and fibula plating in 1 patient who had sustained segmental fracture of fibula. The indications for fibular fixation included the presence of a syndesmotic injury and location of fracture within the distal third of the fibula. In a retrospective study conducted by Whorton et al., fixation of the fibula in fractures of the tibia and fibula has no effect on fracture healing or alignment, but cautioned the need for a prospective study to validate their findings ${ }^{[17]}$. In one patient with isolated transverse tibia fracture, fibulectomy was done. In our study, $11 \mathrm{~mm}$ diameter nail was used in 7 cases, $10 \mathrm{~mm}$ diameter nail in 9 cases, $9 \mathrm{~mm}$ in 11 cases and $8 \mathrm{~mm}$ in 1 patient. All intramedullary interlocking nails were introduced after sufficient reaming. Medullary reaming prepares a uniform canal and improves nail- bone fixation towards the fracture, thus reducing the working length. Reaming helps in introducing a wider diameter nail in the medullary canal compared to undreamed technique. Because the mechanical strength of the nail is directly proportional to its diameter, smaller diameter nails are relatively weak, particularly in bending mode. The narrow nails at the site of locking are also more prone to break in undreamed technique as minimal end osteal contact is present, concentrating the stress at the nailhole junction leading to nail failure or screw breakage ${ }^{[18]}$. Ruiz et.al., in their study in concluded that the strength of intramedullary nails is primaril $y$ determined by their diameter. Dynamization was done in 10 cases in the present study in the 1 st month of follow up. In 2 patients, dynamization was done in the 3 month ${ }^{[19]}$. Bone et.al., treated 29 consecutive patients with tibial nail and followed up prospectively to study the fracture healing pattern. They suggested that dynamization of the nail should be done at 6 weeks to enhance and shorten healing time ${ }^{[20]}$. Ten patients underwent dynamization in the 1st follow up as no adequate callus formation was seen. The other two patients with delayed union still had persisting pain at the fracture site in the 9 month of follow upon full weight bearing.

\section{Conclusion}

Long bone fractures are more common in young adults. Type of surgical procedure has impact on patient's daily life. Application of appropriate surgical procedure can improve the patient's health. Intermedullary interlocking nail method showed significant improvement in closed type of injuries compared to one G\&A type-I and II.

\section{References}

1. Watson-Jones R. Watson-Jones Fractures and Joints. 6 Ed New Delhi: B I Churchill Livingstone 1992.

2. Djahangiri A. Closed and open grade I and II tibial shaft fractures 3 . treated by reamed intramedullary nailing. Med Princ Pract. 2006;15(4):293-8.

3. Sarmiento A. A functional below the-knee cast for tibial fractures.J Bone Joint Surg Am 1967;49:855-75.

4. Wehlan DB, Bhandari M, McKee MD, Guyatt GH, Kreeder HJ, Stephan D et al. Interobserver and intr aobserver variation in the assessment of the healing of tibial fractures after intramedullary fixation. J Bone Joint Sur g Br 2002;84(1):15-8.

5. Hoppenfeld S, deBoer P, Buckley R. The tibia and fibula. Surgical exposures in Orthopaedics - The anatomic app roach. Ed 4h. New Delhi. Wolters Kluwer/Lippincott Williams \& Wilkins 2009, 16-20.

6. Drake Vogl W, Mitchell A. Gray's Anatomy for students. Ed 2nd. Philadelphia : Churchill Livingstone 2008, 542-
84.

7. Samuelson MA, McPherson EJ, Norris L. Anatomic assessment of the proper insertion site for a tibial intramedull ary nail. J Orthop Trauma 2002;16(1):23-5.

8. Bonnevialle $\mathrm{P}$, Bellumore $\mathrm{Y}$, Foucras L, Hézard L, Mansat M. Tibial fracture with intact fibula treated by reamed nailing. Rev Chir Orthop Reparatrice Appar Mot. 2000;86(1):29-37.

9. Bucholz RW, Heckman JD, Bucholz RW, Heckman JD. Rockwood \& Green's Fractures in adults. Ed 6". Philadel phia: Lippincott Williams \& Wilkins 2001.

10. Gustilo RB, Anderson JT. Prevention of infection in the treatment of one thousand and twenty-five open fracture $s$ of long bones: retrospective and prospective analyses. J Bone Joint Surg Am 1976;58:453-8

11. Rüedi TP, Buckley RE, Moran CG. Tibia shaft. In: White RR \& Babikian GM. AO Principles of fracture manage ment. Ed 2ndbexpanded. New York; AO Publishing: 2000, 519-38.

12. Keating JF, O'Brien PJ, Blachut PA, Meek RN, Brooekhuyse M. Locking Intramedullary Nailing with and witho ut Reaming for Open Fractures of the Tibial Shaft. A Prospective, Randomized Study. J Bone Joint Surg Am 1997;79:334-41.

13. Wiss Da Stetson DB. Unstable fractures of the tibia treated with a reamed intramedullary interlocking nail. Clin Orthop Relat Res 1995;315:56-63.

14. Sedlin ED, Zitner DT. The Lottes nail in the closed treatment of tibia fractures. Cinic Orthop Relat Res. 1985;192:185-92.

15. Pandey S, Sharma RK. Kuntscher nailing in tibial shaft fractures. Internat Orthop 1978;2(3):249-54.

16. Hooper GJ, Keddell RG, Penny ID. Conservative management or closed nailing for tibial shaft fractures: A rand omized prospective trial. J Bone Joint Surg Br. 1991;73:83-5.

17. Whorton AM, Henley MB. The role of fixation of the fibula in open fractures of tibial shaft with fractures of the ipsilateral fibula: indications and outcomes. Orthopaedics 1998;21:1101-5.

18. Bhandari M, Guyatt GH, Tong D, Adili A, Shaughnessy SG. Reamed versus nonreamed intermedullary nailing of lower extremity long bone fracture: A systemic review and meta analysis. J Orthop Trauma 2000;14(1):2-9.

19. Ruiz AL, Kealey WD, McCoy GF. Implant failure in tibial nailing. Injury 2000;31(5):359-62

20. Bone LB, Kassman S, Stegemann P, France J. Prospective Study of Union Rate of Open Tibial Fractures Treate d with Locked, Unreamed Intramedullary Nails. J Orthop Trauma 1994;8(1):45-9. 